\title{
Mathematical analysis of catabolic function loss in a population of Pseudomonas putida mt-2 during non-limited growth on benzoate
}

\author{
Wouter A. Duetz, ${ }^{1 *}$ Michael K. Winson, ${ }^{2}$ Johan G. van Andel ${ }^{1}$ and Peter A. Williams ${ }^{2}$ \\ ${ }^{1}$ Laboratory for Waste Materials and Emissions, National Institute of Public Health and Environmental Protection, \\ PO Box 1, 3720 BA Bilthoven. The Netherlands \\ ${ }^{2}$ School of Biological Sciences, University of Wales, Bangor, Gwynnedd LL57 2UW, UK
}

(Received 1 November 1990; revised 20 February 1991; accepted 27 February 1991)

\begin{abstract}
Pseudomonas putida mt-2, harbouring the TOL plasmid PWW0, was grown continuously on benzoate in a phauxostat at a non-limited rate. The gradual decrease in the population carrying the complete TOL plasmid was caused predominantly by a growth-rate advantage of spontaneous mutants carrying a partially deleted plasmid (TOL ${ }^{-}$cells). The growth-rate difference $(v)$ was quantified both by measuring the increase in the dilution rate (from 0.68 to $0.79 \mathrm{~h}^{-1} ; v=0.11 \mathrm{~h}^{-1}$ ) and by mathematical analysis of the ingrowth of TOL- cells $\left(v=0.12 \mathrm{~h}^{-1}\right)$. The latter procedure also established that the segregation rate was of the order of magnitude $10^{-5} \mathbf{h}^{-1}$. Similar values for the growth-rate advantage and the segregation rate were found when both benzoate and succinate were present in non-limiting concentrations. It is suggested that the growth-rate disadvantage of the wild-type strain is caused by inhibitory effects of an intermediate in the degradation of benzoate via the plasmid-encoded metapathway.
\end{abstract}

\section{Introduction}

TOL plasmids encode for the biodegradation of toluene, xylenes and other alkyl substituted benzenes (for a review see Assinder \& Williams, 1990). For a number of strains harbouring a TOL plasmid, it has been shown that growth on benzoate results rapidly in a population that has lost the ability to grow on toluene and xylene (Nakazawa \& Yokota, 1973; Williams \& Murray, 1974; Keshavarz et al., 1985; Stephens \& Dalton, 1987). Genetic analysis demonstrated that these mutants contain either a partially deleted plasmid or no plasmid at all (Bayley et al., 1977; Osborne et al., 1988).

Recent publications have disagreed about the mechanism behind this phenomenon. In general the discussion has concentrated on two possibilities. Williams et al. (1988) stated that the disappearance of the original strain from a pure culture of Pseudomonas putida mt-2 harbouring TOL plasmid pWW0 could be explained adequately by the higher growth rate of spontaneous mutant cells. The relatively high growth-rate advantage of the mutant cells was said to be caused by the use of the chromosomally encoded ortho-pathway for the catabo-

Abbreviation: HMS, 2-hydroxymuconic acid semialdehyde. lism of benzoate. In contrast, Stephens \& Dalton (1987, 1988) proposed that for $P$. putida MT15 carrying TOL plasmid pWW15, benzoate specifically enhances the rate of segregation, and so may cause the gradual disappearance of the wild-type strain even when the wild-type strain is supposed to have no growth-rate disadvantage.

In a number of modelling studies of plasmid instability in other host-vector systems, it has been shown that it is possible to distinguish between the two means of loss of plasmid-encoded functions by analysing the kinetics of disappearance of the organisms bearing the original plasmid (Noack et al., 1984; Cooper et al., 1987; Davidson et al., 1990). By means of a similar model, adapted for growth at maximum rate, we quantified in this study both the growth-rate difference and the segregation rate for $P$. putida $\mathrm{mt}-2$ in phauxostat culture and batch culture, with benzoate or benzoate plus succinate as carbon and energy sources.

\section{Methods}

Nomenclature. Table 1 lists the nomenclature used in this paper.

Bacterial strain. Pseudomonas putida mt-2 (ATCC 33015) harbouring the TOL plasmid $\mathrm{pWW} 0$ was maintained in agar tubes on a mineral 
Table 1. Nomenclature

\begin{tabular}{|c|c|}
\hline C-source & Carbon and energy source \\
\hline$D$ & Dilution rate \\
\hline $\mathrm{OD}_{540}$ & Optical density at $540 \mathrm{~nm}$ \\
\hline$p_{+}$ & $\begin{array}{l}\text { Fraction of the total population with the complete } \\
\text { catabolic TOL function }\end{array}$ \\
\hline$p_{-}$ & $\begin{array}{l}\text { Fraction of the total population lacking the } \\
\text { catabolic TOL function }\end{array}$ \\
\hline$p_{-}^{0}$ & $p_{-}$at $t=0$ \\
\hline$R$ & $\begin{array}{l}\text { Segregation rate (formation rate of cells without } \\
\text { the catabolic TOL function from wild-type cells) }\end{array}$ \\
\hline $\mathrm{TOL}^{+}$cells & $\begin{array}{l}\text { Cells harbouring the complete catabolic TOL } \\
\text { function }\end{array}$ \\
\hline TOL $^{-}$cells & Cells lacking the catabolic TOL function \\
\hline $\mathrm{TOL}^{+}$population & $\begin{array}{l}\text { Part of the total population with the complete } \\
\text { catabolic TOL function }\end{array}$ \\
\hline TOL - population & $\begin{array}{l}\text { Part of the total population lacking the catabolic } \\
\text { TOL function }\end{array}$ \\
\hline$v$ & $\begin{array}{l}\text { Difference in growth rate between the } \mathrm{TOL}^{-} \\
\text {population and the } \mathrm{TOL}^{+} \text {population }\end{array}$ \\
\hline
\end{tabular}

medium with $m$-toluate as the sole carbon and energy source (C-source) at $4{ }^{\circ} \mathrm{C}$. $\mathrm{TOL}^{-}$strains were maintained in the same way but with succinate as the sole $\mathrm{C}$-source.

Media. The growth medium was a mineral salts solution according to Evans et al. (1970), except that the concentrations of all nutrients were decreased to $25 \%$ of the published concentration. Nitrilotriacetate (NTA) was used as a complexing agent. The medium was supplemented with $5 \mathrm{~mm}$-m-toluate (TE-medium), $5 \mathrm{~mm}$ - or $15 \mathrm{~mm}$-benzoate (BE-medium), $10 \mathrm{~mm}$-succinate (SE-medium) or both $15 \mathrm{~mm}$-succinate and $10 \mathrm{~mm}$-benzoate (SBE-medium). For batch growth these media were supplemented with $100 \mathrm{~mm}-\mathrm{K}_{2} \mathrm{HPO}_{4}$ buffer and the $\mathrm{pH}$ was set at $\mathrm{pH} 7.0$ for TE-medium and BE-medium and at $\mathrm{pH} 6.7$ for SE-medium. For fermenter growth TE-medium was supplemented with $10 \mathrm{mM}-$ $\mathrm{K}_{2} \mathrm{HPO}_{4}$ and set at $\mathrm{pH} 6.85$, BE-medium with $2.5 \mathrm{~mm}-\mathrm{K}_{2} \mathrm{HPO}_{4}$ (pH 6.4) and SBE-medium with $50 \mathrm{~mm}-\mathrm{K}_{2} \mathrm{HPO}_{4}(\mathrm{pH} \mathrm{6.55)}$. For fermenter culture, silicone antifoaming agent $(\mathrm{BDH})$ was added to the growth media at a concentration of $62 \mu 11^{-1}$.

phauxostat experiments. The experiments were done in $100 \mathrm{ml}$ glass fermenters, shaped like Erlenmeyer flasks, with a small headspace volume and stirred magnetically at 900 r.p.m. Medium entered at the bottom of the vessel through a needle with an internal diameter of $1 \mathrm{~mm}$. Air was supplied through the same needle at $300 \mathrm{ml} \mathrm{min}^{-1}$. The fermenter was equipped with two stainless steel baffles and kept at $28^{\circ} \mathrm{C}$.

To ensure identical starting conditions for the persistence experiments, the fermenter was fed with a mineral medium containing $\mathrm{m}$ toluate as the sole $\mathrm{C}$-source for $3 \mathrm{~d}$, after inoculation with $30 \mathrm{ml}$ of an overnight batch culture. In this period the culture was carbon- and energy-limited and the dilution rate was increased stepwise to $0.4 \mathrm{~h}^{-1}$. After $3 \mathrm{~d}$ the fermenter was fed with SE-, BE- or SBE-medium. The culture was forced to maximal growth rate by running the fermenter as a phauxostat, as described by Martin \& Hempfling (1976); when the $\mathrm{pH}$ reached 7.02 (due to the conversion of the acid C-source to neutral biomass) the medium pump was switched on automatically ( $\mathrm{pH}$ controller, 500 series, $\mathrm{L} \& \mathrm{H}$ Engineering). The $\mathrm{pH}$ subsequently fell and the pump was switched off automatically at $\mathrm{pH} 6.98$. In this way benzoate or succinate concentrations were stably maintained in excess of $4 \mathrm{~mm}$.

Whenever wall growth was observed, the complete cell suspension was transferred to another sterile fermenter vessel of the same type, without interrupting the addition of medium for more than $1 \mathrm{~min}$.
The dilution rate was calculated by dividing the amount of medium consumed by the length of the time interval $(6-24 \mathrm{~h})$. For plotting and mathematical analysis of dilution rate versus time, the time-point was taken as the middle of the time interval during which the dilution rate was so measured.

Sequential batch growth. Batch experiments were done at $30^{\circ} \mathrm{C}$, with $50 \mathrm{ml}$ of medium in Erlenmeyer flasks $(250 \mathrm{ml})$ shaken at 200 r.p.m. $P$. putida $\mathrm{mt}-2$ was grown overnight in TE-medium and then diluted by $10^{-3}$ in a fresh batch of TE-medium. At the end of the exponential phase (after incubation for about $8 \mathrm{~h}$ ) $10 \mu \mathrm{l}$ of this cell culture was used to inoculate a batch culture in BE-medium ( $5 \mathrm{~mm}$-benzoate). Subsequently, fresh BE-medium cultures were inoculated just before the former batch reached stationary phase (every $8 \mathrm{~h}$ ) by diluting the former $10^{-3}-10^{-4}$, equivalent to about $10^{6}-10^{7}$ cells at the beginning of each batch. The experiment was stopped when no $\mathrm{TOL}^{+}$cells could be detected.

Assay for TOL function loss. At regular intervals, samples were withdrawn from batch or pHauxostat cultures, diluted and plated onto peptone agar. After 1 or $2 \mathrm{~d}$ growth at $30^{\circ} \mathrm{C}$, between 200 and 2000 colonies were screened for the presence of the plasmid-encoded enzyme catechol 2,3-dioxygenase by spraying the agar plates with a $250 \mathrm{~mm}$ catechol solution. The positive colonies turned yellow almost instantly due to the conversion of catechol to 2-hydroxymuconic semialdehyde (Wigmore et al., 1974). This indirect screening method was checked by testing a number of white and yellow colonies for their growth on agar plates with $m$-toluate or succinate as the sole $\mathrm{C}$-source.

Quantification from population dynamics of the growth-rate advantage of $\mathrm{TOL}^{-}$cells. The basic equations for competition in continuous culture at a dilution rate $D$ between two strains $A$ and B present at population fractions $p_{\mathrm{A}}$ and $p_{\mathrm{B}}$, and with growth rates $\mu_{\mathrm{A}}$ and $\mu_{\mathrm{B}}$ were formulated by Cooper et al. (1987).

$$
\begin{gathered}
\left(\frac{\mathrm{d} p_{\mathrm{A}}}{\mathrm{d} t}\right)=\left(\mu_{\mathrm{A}}-D\right) p_{\mathrm{A}} \\
\left(\frac{\mathrm{d} p_{\mathrm{B}}}{\mathrm{d} t}\right)=\left(\mu_{\mathrm{B}}-D\right) p_{\mathrm{B}} \\
\mu_{\mathrm{A}} p_{\mathrm{A}}+\mu_{\mathrm{B}}\left(1-p_{\mathrm{A}}\right)=D
\end{gathered}
$$

In pHauxostat culture $\mu_{\mathrm{A}}$ and $\mu_{\mathrm{B}}$ are considered constant and $D$ is variable. Substitution of equation (3) in equation (1) yields

$$
\left(\frac{\mathrm{d} p_{\mathrm{A}}}{\mathrm{d} t}\right)=v\left(1-p_{\mathrm{A}}\right) p_{\mathrm{A}} \text { with } v=\mu_{\mathrm{A}}-\mu_{\mathrm{B}}
$$

Integration with the boundary condition that $p_{\mathrm{A}}(t=0)=p_{\mathrm{A}}^{0}$ yields

$$
p_{\mathrm{A}}(t)=\frac{p_{\mathrm{A}}^{0}}{p_{\mathrm{A}}^{0}+\left(1-p_{\mathrm{A}}^{0}\right) e^{-v t}}
$$

Equation (5) can be used to describe the competition at non-limited rates between a $\mathrm{TOL}^{+}$cell fraction $p_{+}$and a $\mathrm{TOL}^{-}$cell fraction $p_{-}$, with a growth-rate difference $v=\mu_{-}-\mu_{+}$and an initial fraction of the $\mathrm{TOL}^{-}$population $p_{-}^{0}$.

$$
p_{-}(t)=\frac{p_{-}^{0}}{p_{-}^{0}+\left(1-p_{-}^{0}\right) e^{-r t}}
$$

It can be proven that equation (6) is also valid for sequential batch experiments with the condition that the cells remain in the exponential phase throughout the experiment.

Values for $v$ and $p_{-}^{0}$ were generated by non-linear least-square fitting of equation (6) to the experimental data for the change of $p_{-}$in time, making use of the computer program ENZFITTER (Elsevier Biosoft). In the fitting procedure the datapoints were weighted equally but datapoints with values for $p_{\text {. }}$ of less then $3 \%$ and more then $97 \%$ were ignored. The resulting value for $p_{-}^{0}$ is arbitrary as the contribution of segregation in the initial phase is not taken into account. 
Estimation of segregation rate. When $R$ is defined as the fraction of the strain B population that is transformed to strain A cells per hour, the rate of formation of strain A cells from strain B cells is given by

$$
\left(\frac{\mathrm{d} p_{\mathrm{A}}}{\mathrm{d} t}\right)=R p_{\mathrm{B}}
$$

The total rate of increase of $p_{\mathrm{A}}$ is obtained by summation of equations (1) and (7).

$$
\left(\frac{\mathrm{d} p_{\mathrm{A}}}{\mathrm{d} t}\right)=R p_{\mathrm{B}}+\left(\mu_{\mathrm{A}}-D\right) p_{\mathrm{A}}
$$

When $p_{\mathrm{A}} \ll 1, p_{\mathrm{B}}$ can be approximated by 1 , and in the case of a pHauxostat culture, $\left(\mu_{\mathrm{A}}-D\right)$ can be approximated by $v\left(=\mu_{\mathrm{A}}-\mu_{\mathrm{B}}\right)$. This yields

$$
\left(\frac{\mathrm{d} p_{\mathrm{A}}}{\mathrm{d} t}\right)=R+v p_{\mathrm{A}}
$$

Integration with the boundary condition $p_{\mathrm{A}}(t=0)=0$ yields

$$
p_{\mathrm{A}}=\frac{R\left(e^{r t}-1\right)}{v}
$$

or

$$
R=\frac{v p_{\mathrm{A}}}{e^{\mathrm{tt}}-1}
$$

In the present case of formation of $\mathrm{TOL}^{-}$cells from $\mathrm{TOL}^{+}$cells the segregation rate $R$ can be approximated from the first data point with a reliable value for $p_{-}$by

$$
R=\frac{v p_{-}}{e^{r t}-1}
$$

Analyses. The optical density of cell cultures at $540 \mathrm{~nm}\left(\mathrm{OD}_{540}\right)$ was measured using a Beckman 40 spectrophotometer. The dry weight was determined according to the method of Herbert et al. (1971). Succinate concentrations were determined using an HPLC apparatus (LKB) fitted with a Chromspher $\mathrm{Cl} 8$ reversed phase column (Chrompack), a UV-detector (LKB) set at $210 \mathrm{~nm}$ and an C-R3A integrator (Shimadzu). The column temperature was ambient $\left(18-22^{\circ} \mathrm{C}\right)$ and the eluent was $5 \mathrm{~mm}-\mathrm{H}_{2} \mathrm{SO}_{4}$. The concentration of benzoate was determined spectrophotometrically at $225 \mathrm{~nm}$.

\section{Genetic characterization of phenotypical TOL- mutants}

$\mathrm{TOL}^{-}$mutants were assayed for the presence of plasmid DNA by one or both of the following methods.

(1) Plasmid extraction, purification and detection on an agarose gel. This was done according to the method of Kado \& Liu (1981) with the following changes. Cell cultures $(1.5 \mathrm{ml})$ were grown overnight in SEmedium in Eppendorf tubes at $30^{\circ} \mathrm{C}$ and subsequently centrifuged and resuspended in $30 \mu \mathrm{l}$ of water. Cells were lysed by the addition of $30 \mu \mathrm{l}$ of a solution of $125 \mathrm{~mm}-\mathrm{Tr}$ is, $80 \mathrm{~mm}-\mathrm{NaOH}$ and $2.5 \%(\mathrm{w} / \mathrm{v}) \mathrm{SDS}$, followed by incubation at $65{ }^{\circ} \mathrm{C}$ for $30 \mathrm{~min}$. HindIII restriction analysis was done as described by Wheatcroft $\&$ Williams (1981).

(2) Colony hybridization. A sample of $\mathrm{TOL}^{-}$colonies (detected by spraying with catechol) were maintained in $8 \times 6$ arrays on peptone agar plates. After incubation for $18 \mathrm{~h}$ at $30^{\circ} \mathrm{C}$ the colonies were transferred to a Biodyne nylon filter membrane (Pall Ultrafine Filtration Corp.) using a replicating device. The membrane was laid onto filter paper (Whatman 3MM) soaked in $10 \%(\mathrm{w} / \mathrm{v})$ SDS for $5 \mathrm{~min}$ to lyse the cells, followed by $0.5 \mathrm{M}-\mathrm{NaOH} / 1.5 \mathrm{M}-\mathrm{NaCl}(5 \mathrm{~min})$ and $3 \mathrm{M}-$ Tris $/ 1.5 \mathrm{M}-\mathrm{NaCl}(5 \mathrm{~min})$. The membrane was air-dried and then heated at $80^{\circ} \mathrm{C}$ for $2 \mathrm{~h}$. Nick-translation and hybridization were done as described by Keil \& Williams (1985), using the HindIII fragment HI from pWW0 cloned into pKT230 as the radiolabelled probe. The HindIII fragment was separated from the vector DNA by agarose gel electrophoresis and extracted according to Girvitz et al. (1980).
Statistics. For the average values of the optical density and for the calculated values of the growth-rate difference $v$, the double standard deviations $(2 \sigma)$ of the individual data are given. For the average dilution rates at the beginning and end of the phauxostat experiments, the double standard error of the mean was calculated [this results in a $95 \%$ reliability interval for the mean values of $\bar{x}$ of $(\bar{x}-1.96 \sigma, \bar{x}+1.96 \sigma)]$. For the individual determinations of the fractions of $\mathrm{TOL}^{+}$cells, $95 \%$ reliability intervals were calculated and are presented in the graphs. We assumed a binomial distribution, approximated by the normal distribution.

\section{Results}

\section{Growth of $P$. putida mt-2 on benzoate in a phauxostat}

Non-limited growth of $P$. putida mt-2 on benzoate was achieved through control of the fermenter medium pump by the $\mathrm{pH}$ of the culture. In this system (phauxostat) a residual concentration of $4 \mathrm{mM}$-benzoate (out of $15 \mathrm{~mm}$ in the ingoing medium) could be maintained stably throughout the experiment. The biomass remained fairly constant $\left(\mathrm{OD}_{540}=1.02 \pm 0.05\right.$, corresponding to a dry weight of about $550 \mathrm{mg} \mathrm{l}^{-1}$ ) indicating a constant growth yield.

During the course of the experiment $(120 \mathrm{~h})$ the percentage of the population harbouring the complete TOL plasmid ( $\mathrm{TOL}^{+}$population) dropped from $100.0 \%$ to below $0.5 \%$ (see Fig. $1 a$ ). In the period when the percentage of the $\mathrm{TOL}^{+}$population was over $99 \%(50 \mathrm{~h}$, 33 vessel volume changes) the dilution rate remained constant at $0.68 \pm 0.01 \mathrm{~h}^{-1}$. During the stage that the percentage of the TOL population dropped to below $1 \%$, the dilution rate increased and eventually stabilized at $0.79 \pm 0.01 \mathrm{~h}$. The cell density remained constant so it may be assumed that this increase in the dilution rate of $0.11 \pm 0.02 \mathrm{~h}^{-1}$ is equal to the growth-rate advantage $v$ of the $\mathrm{TOL}^{-}$population.

Fitting equation (6) to the data points for the percentage of the $\mathrm{TOL}^{+}$population in the course of the experiment generates a value for $v$ of $0.12 \pm 0.02 \mathrm{~h}^{-1}$.

It is not possible to determine low percentages (below $1 \%$ ) of the $\mathrm{TOL}^{-}$population accurately. Therefore, in the initial stage of the experiment we could not distinguish segregation from the faster growth of already existing $\mathrm{TOL}^{-}$cells by mathematical analysis. If, at the start of the experiment, the fraction of $\mathrm{TOL}^{-}$cells was $0.008 \%$, their faster growth could be solely responsible for the results presented in Fig. $1(a)$. Assuming, however, that at time $t=0$ the population consisted solely of the original strain $\left(p_{-}^{0}=0\right)$, a maximal value for the segregation rate can be calculated. For this purpose we applied equation (12) to the first data point in which $p_{-}$ could be determined with reasonable accuracy ( $p_{-}=0.011$ at $t=46.5 \mathrm{~h}$ ) assuming a constant value for $v$ of $0.11 \mathrm{~h}^{-1}$. This yielded a value for the segregation rate $R$ of $7 \times 10^{-6} \mathrm{~h}^{-1}$. 

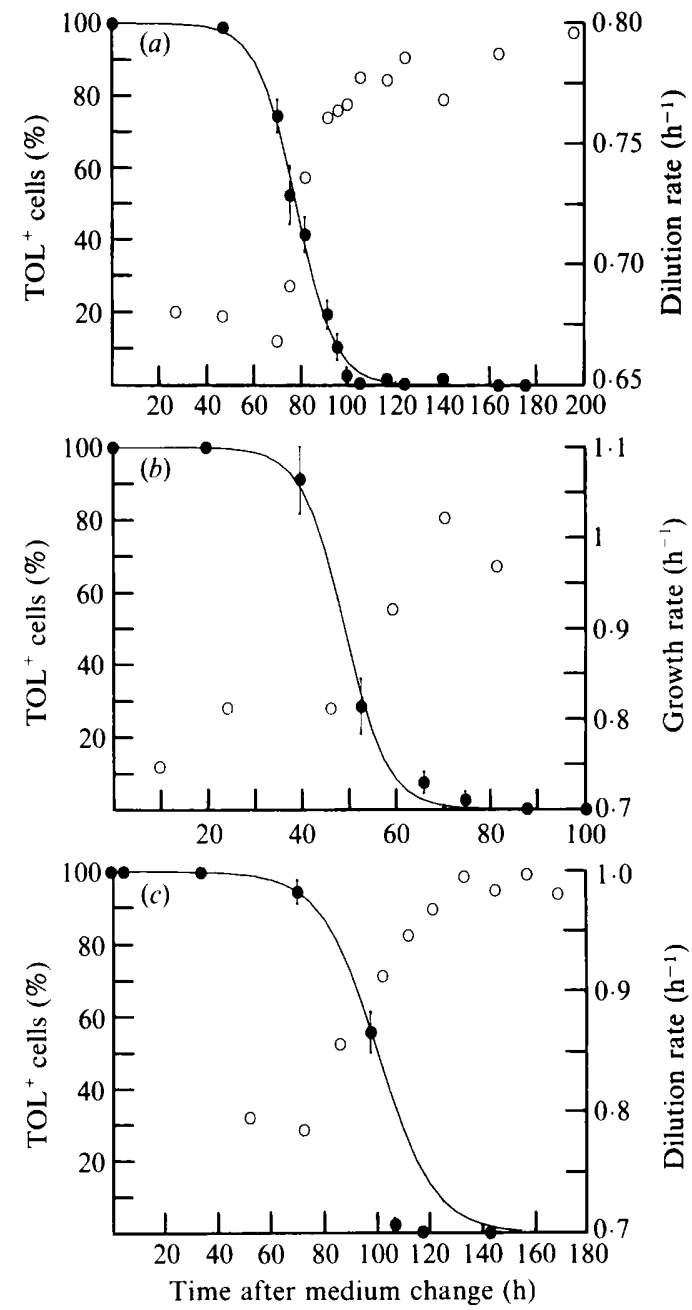

Fig. 1. Persistence of plasmid PWW0 in $P$. putida mt-2 grown at nonlimited rate on $(a)$ benzoate in phauxostat culture, $(b)$ benzoate in sequential batch culture and $(c)$ both benzoate and succinate in phauxostat culture. $\bigcirc$, Dilution rate or growth rate $\left(\mathrm{h}^{-1}\right) ; 0$, fraction $p_{+},($error bars indicate $95 \%$ reliability intervals); - - best-fit curve of equation (6) (see Methods) to the experimental values of $p_{+}$, generating values for the growth-rate difference $v$ of $(a) 0.12 \mathrm{~h}^{-1},(b) 0.22 \mathrm{~h}^{-1}$ and (c) $0.095 \mathrm{~h}^{-1}$, and for the initial fraction $p_{-}^{0}$ of $(a) 8.4 \times 10^{-5},(b)$ $2.0 \times 10^{-5}$ and $(c) 1.1 \times 10^{-5}$.

Growth of P. putida mt-2 on benzoate in sequential batch culture

In order to facilitate comparison of our results with previous studies, $P$. putida strain $\mathrm{mt}-2$ was also grown on benzoate in sequential batches. The results, although inherently less accurate, are similar to those of the phauxostat system with respect to the offset of significant ingrowth of a $\mathrm{TOL}^{-}$population and the growth-rate difference derived from equation (6) $(v=0.22 \pm$ $\left.0.08 \mathrm{~h}^{-1}\right)$. This value for $v$ is in agreement with the growth rate increase of $0.2 \mathrm{~h}^{-1}$ found in the subsequent batches upon ingrowth of the $\mathrm{TOL}^{-}$population (from
0.75 to $0.96 \mathrm{~h}^{-1}$; see Fig. $1 b$ ). The value for the segregation rate $R$ derived from the batch experiments $\left(4 \times 10^{-6} \mathrm{~h}^{-1}\right)$ is of the same order of magnitude as the value for $R$ derived from the phauxostat experiment.

\section{Growth of P. putida mt-2 on a mixture of benzoate and succinate in a phauxostat}

Experiments in the phauxostat similar to those described above were done, but with a growth medium containing both succinate and benzoate as $\mathrm{C}$-sources (SBE-medium). The culture consumed approximately $4 \mathrm{~mm}$-benzoate and $6 \mathrm{~mm}$-succinate simultaneously while the residual concentrations were $6 \mathrm{~mm}$ and $9 \mathrm{~mm}$ respectively. The dilution rate was initially $0.79 \pm 0.02 \mathrm{~h}^{-1}$ and increased gradually to $0.98 \pm 0.02 \mathrm{~h}^{-1}$ after the $\mathrm{TOL}^{+}$population was replaced almost completely by a $\mathrm{TOL}^{-}$population (see Fig. $1 c$ ). Thus the value for $v$ determined from the dilution rates was $0 \cdot 19 \mathrm{~h}^{-1}$, while the value for $v$ derived by fitting equation (6) to the data points was $0 \cdot 10 \mathrm{~h}^{-1}$. The latter value, however, is not very reliable due to a smaller data set. The (maximal) segregation rate was calculated to be $5 \times 10^{-8} \mathrm{~h}^{-1}$. The $\mathrm{OD}_{540}$ in this experiment was $0 \cdot 80$.

\section{Reproducibility of phauxostat results}

The experiments with benzoate as sole C-source were reproducible. Two duplicate experiments (data not given) gave values for $v$ and $R$ that were very similar to the experiment presented in this paper. These data were less accurate mainly due to a lower frequency of sampling and therefore they are not presented.

The phauxostat experiments with a mixture of benzoate and succinate, however, showed less consistency. In particular, the time at which the $\mathrm{TOL}^{-}$ population became predominant varied in repeat experiments. In all repeat experiments, however, the $\mathrm{TOL}^{-}$ population eventually took over at a rate that was comparable to the experiment presented here in detail.

\section{Genetic characterization of $\mathrm{TOL}^{-}$mutants}

All $\mathrm{TOL}^{-}$mutants appeared to contain plasmids of $78 \mathrm{~kb}$. HindIII restriction patterns were identical to that of plasmid pWW0-8, a derivative of $\mathrm{pWW} 0$ lacking all TOL catabolic genes (Meulien et al., 1981). Neither during the pHauxostat experiment (48 colonies tested) nor during the two sequential batch experiments (more than 100 colonies tested) were plasmid-free mutants found.

This is in agreement with previous benzoate curing experiments in batch culture where a vast majority of the $\mathrm{TOL}^{-}$cells contained a partially deleted plasmid (Williams et al., 1988). 


\section{Discussion}

The use of a phauxostat was shown to be a reliable way to grow $P$. putida mt-2 on benzoate at a non-limited growth rate for a prolonged period of time. Starting with a $\mathrm{TOL}^{+}$population, the dilution rate increased during the course of the experiment concomitantly with the gradual takeover by a $\mathrm{TOL}^{-}$population. The growth-rate difference derived from the difference in the initial and final average dilution rates $\left(0.11 \mathrm{~h}^{-1}\right)$ is in good agreement with the growth-rate difference derived from the kinetics of ingrowth of the $\mathrm{TOL}^{-}$population $\left(0.12 \mathrm{~h}^{-1}\right)$. This represents a $15 \%$ faster growth rate of the $\mathrm{TOL}^{-}$population compared to the $\mathrm{TOL}^{+}$population.

From the stage in the phauxostat experiment in which the culture contained maximally $2 \%$ of $\mathrm{TOL}^{-}$cells the segregation rate was estimated to be $7 \times 10^{-6} \mathrm{~h}^{-1}$. This value may be too low in the case that segregants may also appear that do not have a growth-rate advantage. More probable, however, is that this value is an overestimation because of the assumption in the calculations that there were no $\mathrm{TOL}^{-}$cells at the start of the experiment. In any case it indicates that the segregation rate with benzoate as a $\mathrm{C}$-source is not abnormally high when compared to the segregation rate observed for the same organism with succinate as C-source (see accompanying paper: Duetz \& van Andel, 1991), or compared to other values for segregation rates of relatively stable plasmids (e.g. Cooper et al., 1987).

We calculated the relative contribution of the growthrate difference and the rate of segregation to the loss of the TOL catabolic function in phauxostat culture for different fractions $\left(p_{-}\right)$of the $\mathrm{TOL}^{-}$population (see Table 2). The table shows that after $p_{-}$surpasses $0.01 \%$, the growth-rate difference is the predominant factor in the gradual takeover of the culture by the $\mathrm{TOL}^{-}$ population. Furthermore, these calculations demonstrate that it is not necessary to include the contribution of segregation in the applied method for deriving a value for $v$ from the kinetics of increase of the $\mathrm{TOL}^{-}$ population from $3 \%$ to $97 \%$. The contribution of segregation to the increase in the $\mathrm{TOL}^{-}$population is less than $1 \%$ during this stage. The values found for the growth-rate difference and the segregation rate are not significantly different when determined in sequential batch cultures. The higher growth rates found in sequential batch culture may be caused partially by a lower average cell density and a higher temperature $\left(30^{\circ} \mathrm{C}\right.$ versus $\left.28^{\circ} \mathrm{C}\right)$.

The rationale behind the growth-rate disadvantage of the $\mathrm{TOL}^{+}$cells remains unclear. A similar growth-rate difference was observed when succinate and benzoate were present simultaneously (Fig. 1c), while almost no growth-rate difference was observed with succinate
Table 2. Relative contribution of segregation and growthrate difference to the disappearance of the $\mathrm{TOL}^{+}$population of $P$. putida mt-2 during non-limited growth on benzoate, for different values of $p_{-}$

For the calculations we used equations (4) and (7) (see Methods) and the values for $R$ and $v$ derived from the pHauxostat experiment shown in Fig. $1(a)$.

\begin{tabular}{cccccc}
\hline \hline & \multicolumn{2}{c}{$D p_{-} / \mathrm{d} t\left(\mathrm{~h}^{-1}\right)$} & & \multicolumn{2}{c}{ Relative contribution (\%) } \\
\cline { 2 - 3 } \cline { 5 - 6 }$p_{-}$ & $\begin{array}{c}\text { Segregation } \\
\text { rate }\end{array}$ & $\begin{array}{c}\text { Growth-rate } \\
\text { difference }\end{array}$ & & $\begin{array}{c}\text { Segregation } \\
\text { rate }\end{array}$ & $\begin{array}{c}\text { Growth-rate } \\
\text { difference }\end{array}$ \\
\hline $10^{-6}$ & $7.00 \times 10^{-6}$ & $1.07 \times 10^{-7}$ & & 98.49 & 1.51 \\
$10^{-4}$ & $7.00 \times 10^{-6}$ & $1.07 \times 10^{-5}$ & & 39.55 & 60.45 \\
$10^{-2}$ & $6.93 \times 10^{-6}$ & $1.06 \times 10^{-3}$ & & 0.65 & 99.35 \\
0.1 & $6.30 \times 10^{-6}$ & $9.63 \times 10^{-3}$ & & 0.07 & 99.93 \\
0.5 & $3.50 \times 10^{-6}$ & $2.67 \times 10^{-2}$ & & 0.01 & 99.99 \\
\hline \hline
\end{tabular}

alone (for the latter results see the accompanying paper: Duetz \& van Andel, 1991). As benzoate was not necessary to sustain growth, this suggests that the previously proposed greater kinetic efficiency of the ortho-pathway (e.g. Williams et al., 1988) cannot be solely responsible for the lower growth rate of the $\mathrm{TOL}^{+}$ population.

The growth rate of $\mathrm{TOL}^{+}$cells when both benzoate and succinate are present simultaneously is lower than when succinate is the sole $\mathrm{C}$-source. The growth rate of $\mathrm{TOL}^{-}$cells on succinate, however, is unchanged by the additional presence of benzoate. These results indicate that benzoate is causing an inhibitory effect specific to $\mathrm{TOL}^{+}$cells. This has been proposed previously by Stephens \& Dalton (1987) who found that benzoate had a strong inhibitory effect when $P$. putida MT15 was grown on gluconate. However, Stephens \& Dalton (1987) stated that the subsequent increase in the fraction of $\mathrm{TOL}^{-}$cells was too rapid to be explained simply by the growth-rate difference. An additional explanation, they assumed, was that benzoate induced segregational instability of the plasmid. According to our calculations, however, the reported lag phase of about 20 generations before a significant $\mathrm{TOL}^{-}$population is detectable rules out the possibility that segregation makes an important contribution to the disappearance of $\mathrm{TOL}^{+}$cells. If - under some conditions - the decrease in the fraction of $\mathrm{TOL}^{+}$ cells is indeed too fast to be explained by the growth-rate difference (also observed by us at low percentages of $\mathrm{TOL}^{+}$cells, see Fig. $1 a$ and $1 c$ ), the cause may be a difference in viability of the two populations on the agar test plates.

It is improbable that the inhibitory effect of benzoate on $\mathrm{TOL}^{+}$cells is caused only by the extra energy expenditure on the expression of enzymes of the metapathway. An alternative possibility would be that an 
accumulating meta-pathway intermediate, such as 2hydroxymuconic semialdehyde (HMS), is inhibitory. It was found (data not shown) that during growth on benzoate extracellular concentrations of $0.2 \mathrm{~mm}$-HMS may occur. It is possible that the intracellular concentrations are even higher. The accumulation of HMS is caused by the very high specific activities of benzoate oxidase and catechol 2,3-dioxygenase for benzoate and catechol respectively (Murray et al., 1972).

Further research needs to be done in order to quantify the energetic burden that TOL plasmids put on their host and to identify possible specific inhibitory effects of pathway intermediates.

\section{References}

Assinder, S. J. \& Williams, P. A. (1990). The TOL plasmids: determinants of the catabolism of toluene and the xylenes. Advances in Microbial Physiology 31, 1-70.

Bayley, S. A., Duggleby, C. J., Worsey, M. J., Williams, P. A., HARDY, K. G. \& Broda, P. (1977). Two modes of loss of the TOL function from Pseudomonas putida mt-2. Molecular and General Genetics 154, 203-204.

COOPER, N. S., Brown, M. E. \& CAulcott, C. A. (1987). A mathematical method for analysing plasmid stability in microorganisms. Journal of General Microbiology 133, 1871-1880.

Davidson, A. M., Dunn, A., Day, M. J. \& Randerson, P. F. (1990). A nonlinear technique for the analysis of plasmid instability in microorganisms. Journal of General Microbiology 136, 59-64.

DueTZ, W. A. \& VAN ANDEL, J. G. (1991). Stability of TOL plasmid pWW0 in Pseudomonas putida $\mathrm{mt}-2$ under non-selective conditions in continuous culture. Journal of General Microbiology 137, 1369-1374.

Evans, C. G. T., Herbert, D. \& Tempest, D. W. (1970). The continuous cultivation of microorganisms. 2. Construction of a chemostat. Methods in Microbiology 2, 277-327.

Girvitz, S. C., Bacchetti, S., Rainbow, A. J. \& Graham, F. W (1980). A rapid and efficient procedure for the purification of DNA from agarose gels. Analytical Biochemistry 106, 492-496.

Herbert, D., Phipps, P. J. \& Strange, R. E. (1971). Chemical analysis of microbial cells. Methods in Microbiology 5B, 209-344.

KADO, C. I. \& LIU, S. T. (1981). Rapid procedure for detection and isolation of large and small plasmids. Journal of Bacteriology 145, $1365-1373$.
KeIL, H. \& Williams, P. A. (1985). A new class of TOL plasmid deletion mutants in Pseudomonas putida MT15 and their reversion by tandem gene amplification. Journal of General Microbiology 131, 1023-1033

Keshavarz, T., Lilly, M. D. \& Clarke, P. H. (1985). Stability of a catabolic plasmid in continuous culture. Journal of General Microbiology 131, 1193-1203.

Martin, G. A. \& Hempfling, W. P. (1976). A method for the regulation of microbial population density during continuous culture at high growth rates. Archives of Microbiology 107, 41-47.

Meulien, P., Downing, R. G. \& Broda, P. (1981). Excision of the $40 \mathrm{~kb}$ segment of the TOL plasmid from Pseudomonas putida $\mathrm{mt}-2$ involves direct repeats. Molecular and General Genetics 184, 97-101.

Murray, K., Duggleby, C. J., Sala-Trepat, J. M. \& Williams, P. A (1972). The metabolism of benzoate and methylbenzoates via the meta-cleavage pathway by Pseudomonas arvilla $\mathrm{mt}-2$. European Journal of Biochemistry 28, 301-310.

Nakazawa, T. \& Yokota, T. (1973). Benzoate metabolism in Pseudomonas putida (arvilla) mt-2: demonstration of two benzoate pathways. Journal of Bacteriology 115, 262-267.

NoACK, D., Muller, G. \& Roth, M. (1984). Mathematical modelling of genetic segregation kinetics obtained with chemostat cultures of procaryotic microorganisms. Zeitschrift für Allgemeine Mikrobiologie 24, 459-465.

Osborne, D. J., Pickup, R. W. \& Williams, P. A. (1988). The presence of two complete homologous meta pathway operons on TOL plasmid pWW53. Journal of General Microbiology 134, 2965-2975.

StePhENS, G. M. \& Dalton, H. (1987). The effect of lipophilic weak acids on the segregational stability of TOL plasmids in Pseudomonas putida. Journal of General Microbiology 133, 1891-1899.

Stephens, G. M. \& Dalton, H. (1988). Kinetics of benzoate-induced loss of the TOL plasmid from Pseudomonas putida MT15 during growth in chemostat culture. FEMS Microbiology Letters 55, 175-180.

WhEATCROFT, R. \& Williams, P. A. (1981). Rapid method for the study of both stable and unstable plasmids in Pseudomonas. Journal of General Microbiology 124, 433-437.

Wigmore, G. J., Bayly, R. C. \& Di Berardino, D. (1974). Pseudomonas putida mutants defective in the metabolism of the products of meta fission of catechol and its methyl analogues. Journal of Bacteriology 120, 31-37.

Williams, P. A. \& MurRay, K. (1974). Metabolism of benzoate and the methylbenzoates by Pseudomonas putida (arvilla) $\mathrm{mt}-2$ : evidence for the existence of a TOL plasmid. Journal of Bacteriology 120, 416-423.

Williams, P. A., Taylor, S. D. \& GibB, L. E. (1988). Loss of the toluene-xylene catabolic genes of TOL plasmid pWW0 during growth of Pseudomonas putida on benzoate is due to a selective growth advantage of 'cured' segregants. Journal of General Microbiology 134, 2039-2048. 